\title{
Irinotecan overcomes the resistance to 5-fluorouracil in human colon cancer xenografts by down-regulation of intratumoral thymidylate synthase
}

\author{
MASAKAZU FUKUSHIMA ${ }^{1}$, KAZUKI SAKAMOTO ${ }^{1}$, HIDEYUKI OHSHIMO ${ }^{1}$, \\ FUMIO NAKAGAWA ${ }^{1}$ and TETSUO TAGUCHI ${ }^{2}$ \\ ${ }^{1}$ Tokushima Research Center, Taiho Pharmaceutical Co., Ltd., 224-2 Hiraishi-ebisuno, Kawauchi, Tokushima 771-0194; \\ ${ }^{2}$ Japan Society for Cancer Chemotherapy, 1-18-35 Edobori, Nishi-ku, Osaka 505-0002, Japan
}

Received May 13, 2010; Accepted July 12, 2010

DOI: $10.3892 /$ or_00000927

\begin{abstract}
To clarify the molecular interaction of irinotecan (CPT-11) and oxaliplatin (l-OHP) in combination with 5fluorouracil (5-FU), the antitumor effects of CPT-11 and $l$ OHP combined with the oral 5-FU prodrug, S-1 composed by tegafur, gimeracil and potassium oteracil, were investigated on human colon cancer KM12C xenografts sensitive or resistant to 5-FU in nude mice. In parental KM12C tumor xenografts, combined treatment of CPT-11 with oral S-1 significantly augmented the antitumor activity compared with those of CPT-11 and S-1 alone. Interestingly, combined therapy of CPT-11 with S-1 was markedly effective with almost $90 \%$ of inhibition of tumor growth on 5-FU-resistant tumors (KM12C/ 5-FU), and its potency likely corresponded to that in parental tumors. In contrast, combined administration of $l$-OHP with S-1 did not shown an effect on KM12C/5-FU tumor xenografts. To investigate why only CPT-11 potentiated the antitumor activity in combination with 5-FU pro-drugs against 5-FU-resistant colon tumors, the activities or expression levels of thymidylate synthase (TS), ribonucleotide reductase (RNR) and other enzymes in 5-FU-metabolism in both tumors were measured following administration of CPT-11 and/or $l$-OHP. CPT-11, but not $l$-OHP, induced a decrease in activities and protein levels of TS and an increase in those of RNR in KM12C/5-FU tumors only, which was likely related to decreased expressions of several proteins in G1/S phase of the cells including CDK4, pRB, and E2F1 in these tumors. These findings suggest that CPT-11, but not $l$ OHP, would overcome the resistance to 5-FU in combination with 5-FU pro-drugs on 5-FU-resistant colon tumors.
\end{abstract}

Correspondence to: Dr Masakazu Fukushima, Tokushima Research Center, Taiho Pharmaceutical Co., Ltd., 224-2 Hiraishiebisuno, Kawauchi, Tokushima 771-0194, Japan

E-mail: fukusima@taiho.co.jp

Key words: S-1, 5-FU, irinotecan, l-OHP, thymidylate synthase

\section{Introduction}

Colorectal cancer is the most frequent malignancy in the world and various clinical approaches are attempting to improve response rate and overall survival of patients with advanced colorectal cancer by the combination of cytotoxic drugs and/or addition of molecular targeted agents to cytotoxic regimens.

5-Fluorouracil (5-FU) is a basic drug for the treatment of colorectal cancer and is widely used in combination with leucovorin (LV) in the FU/LV regimen (1-3), oxaliplatin ( $l$-OHP) in the FOLFOX regimen $(4,5)$ or irinotecan (CPT-11) in the FOLFIRI $(6-9)$ and IFL $(10,11)$ regimens.

5-FU is metabolized to its active form, 5-fluoro-2'deoxyuridine 5'-monophosphate (FdUMP) to bind and inhibit thymidylate synthase (TS), a rate-limiting enzyme of DNA synthesis, then exerting antitumor activity, however, 5-FU is rapidly degraded to its inactive form in the liver and tumors. To improve the metabolic defects of 5-FU and to further potentiate the antitumor efficacy of 5-FU, several oral prodrugs of 5-FU such as UFT (tegafur-uracil), capecitabine and $\mathrm{S}-1$ have been developed.

$\mathrm{S}-1$ is the combined form of 1 molar tegafur, 0.4 molar gimeracil which inhibits dihydropyrimidine dehydrogenase in the liver and tumors, and 1 molar potassium oteracil, an inhibitor of orotate phosphoribosyltransferase to inhibit the phosphorylation of 5-FU in the gastrointestinal tract (12). $\mathrm{S}-1$ has been reported to obtain a high clinical response in ganstrointestinal cancers (13-15).

Recently, the expression of TS, response-limiting enzyme (gene) of 5-FU, has been suggested to influence to clinical outcome such as response rate and survival in cancer patients received 5-FU-based chemotherapy. Salonga et al (16) have reported that colon cancer patients with higher expression levels of TS mRNA in addition of DPD and TP showed a shorter survival time than those with lower expression of TS mRNA after treatment with 5-FU plus LV. Ichikawa et al reported that gastric cancer patients with higher expression level of TS mRNA, but not DPD mRNA did not respond to S-1 chemotherapy (17). As to the relationship between TS expression in tumors and 5-FU response, Leichman (18) have reviewed that colorectal 
cancer patients with low TS would be likely to benefit from 5-FU/LV therapy, whereas patients whose tumors express high TS levels may benefit from CPT-11. In terms of the combination of 5-FU with CPT-11, there are several reports resulting in augmented or synergistic antitumor activity on colorectal cancer cells in vitro (19-21) and in vivo $(19,22,23)$, and that this effect is based on potentiated tumoral DNA damage formation. The combination of $l$-OHP with 5 -FU have also been reported to show the synergistic cytotoxicity on colon cancer cells $(24,25)$.

We developed acquired-resistant colorectal cancer xenografts to 5-FU in vivo following long-term treatment with infusion of 5-FU and characterized in these tumors as an increased TS expression and decreased RNR activity (26).

We, therefore, sought to determine whether CPT-11 or $l$-OHP in combination with 5-FU could overcome resistance to 5-FU and whether CPT-11 plays a role in regulating the expression of TS and RNR via the control of cell cyclesignaling proteins in colorectal tumor xenografts with acquired resistance to 5 -FU.

\section{Materials and methods}

Chemicals. Irinotecan (CPT-11) and oxaliplatin (l-OHP) were obtained from Daiichi Pharmaceutical Co., Ltd., (Tokyo, Japan) and Sinopharm Jiangsu Co., Ltd. (Takao, Taiwan). Tegafur (FT), Gimeracil and potassium oteracil were products from Taiho Pharmaceutical Co., Ltd. S-1 is a combined form of 1 molar FT, 0.4 molar Gimeracil and 1 molar potassium oteracil. $\left[6-{ }^{3} \mathrm{H}\right]-5-\mathrm{FU}(525 \mathrm{GBq} / \mathrm{mmol})$, [6- $\left.{ }^{3} \mathrm{H}\right]$-thymidine (dThd; $\left.2.41 \mathrm{TBq} / \mathrm{mmol}\right),\left[6-{ }^{3} \mathrm{H}\right]-\mathrm{FdUMP}$ $(625 \mathrm{GBq} / \mathrm{mmol})$, and $\left[(\mathrm{U})-{ }^{14} \mathrm{C}\right]$-cytidine-5'-diphosphate (CDP; $2.04 \mathrm{GBq} / \mathrm{mmol}$ ) were obtained from Moravek Biochemicals, Inc. (Brea, CA). For immunoblot analysis of proteins, anti-TS antibody was prepared by us (27), and antibodies against cyclin-dependent kinase 4 (CDK-1), phosphorylated retinoblastoma (pRB), E2F1 and B-actin used were purchased from Santa Cruz Biochemicals Inc. (San Diego, CA).

Tumor xenografts. Human colon tumor KM12C xenografts were obtained from Dr K. Morikawa (Iwamizawa Worker's Comprehensive Hospital, Hokkaido, Japan) and maintained by serial implantation into the right axilla of nude mice at 3-week intervals. KM12C/5-FU tumors resistant to 5-FU were established in our laboratories (26).

Antitumor experiments. Groups of 8 nude mice were used. $\mathrm{KM} 12 \mathrm{C}$ and $\mathrm{KM} 12 \mathrm{C} / 5-\mathrm{FU}$ tumors were prepared by s.c. implantation of approximately 3-mm fragments into the right axilla of mice. When the tumor volume reached to about $200 \mathrm{~mm}^{3}, \mathrm{~S}-1(8.3 \mathrm{mg} / \mathrm{kg})$ was administered orally for 14 consecutive days, and CPT-11 $(75 \mathrm{mg} / \mathrm{kg})$ or $l$-OHP $(10 \mathrm{mg} /$ $\mathrm{kg}$ ) was injected i.v. on day 1 and 8 . The tumor volume $[1 / 2$ $\mathrm{x}$ (the major axis) $\mathrm{x}$ (the minor axis) $\left.{ }^{2}\right]$ was measured twice a week throughout the treatment periods (14 days), and relative tumor volume (RTV) was calculated as follows: RTV = (mean tumor volume during therapy)/(mean tumor volume at the beginning of the therapy). The antitumor effects of S-1, CPT-11 and their combination were estimated by the
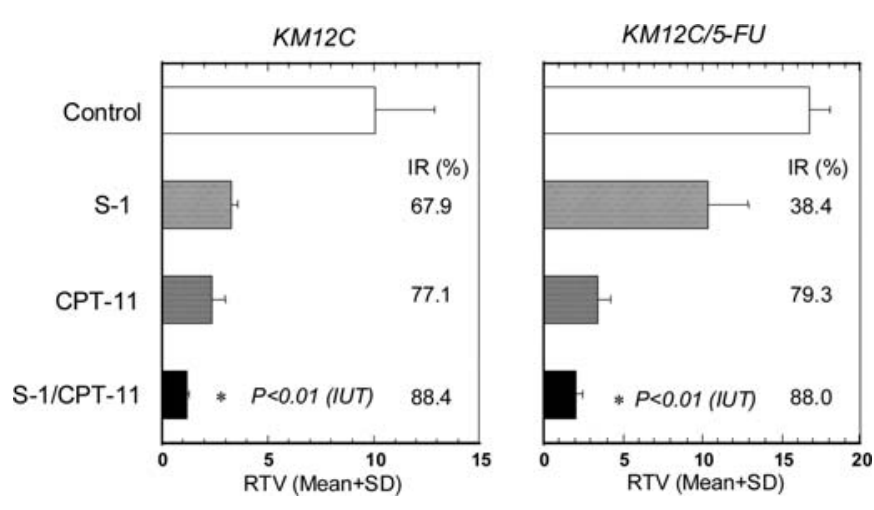

Figure 1. Antitumor effects of S-1, CPT-11, and their combination on parental and 5-FU-resistant human colon cancer, KM12C xenografts in nude mice. S-1 (8.3 mg/kg/day) was orally given for 14 consecutive days and CPT-11 (75 mg/kg) was intravenously administered on days 1 and 8 , and 14 days after, each relative tumor volume in each treated group was measured and IR of the tumor growth was calculated. ${ }^{*} \mathrm{P}<0.01$, significantly different from S-1 alone and CPT-11 alone (IUT test).

following equation: mean inhibition rate of tumor growth $(\mathrm{IR}, \%)=[1-($ mean RTV of drug-treated group/mean RTV of control group) x 100]. All animal experiments were conducted according to the institutional guidelines and conforming to international rules.

Enzyme assay. Parental and its 5-FU-resistant KM12C tumors were homogenized with 3 volumes of $50 \mathrm{mM}$ Tris- $\mathrm{HCl}(\mathrm{pH}$ 7.6) containing $10 \mathrm{mM}$ 2-mercaptoethanol, $25 \mathrm{mM} \mathrm{KCl}$ and $5 \mathrm{mM} \mathrm{MgCl}_{2}$, centrifuged at 105,000 x g for $60 \mathrm{~min}$, and the resulting supernatant was used to measure enzyme activity. Enzymes measured in this study were TS, DPD, ribonucleotide reductase (RNR), orotate phosphoribosyltransferase (OPRT), and thymidine phosphorylase (TP). TS was measured by the $\left[6-{ }^{3} \mathrm{H}\right]-$ FdUMP binding assay based on the method of Spears et al (28). DPD and OPRT activity was determined according to the method of Shirasaka et al (29) using $\left[6-{ }^{3} \mathrm{H}\right]-5-\mathrm{FU}$ as the substrate. TP was measured according to the modified method described by Ikenaka et al (30) and Maehara et al (31). Ribonucleotide reductase activity was determined using $\left[(\mathrm{U})-{ }^{14} \mathrm{C}\right]-\mathrm{CDP}$ as the substrate as described previously (26).

Western blot analysis. Aliquots of the supernatant described above were subjected to Western blot analysis. The supernatant was heated for $2 \mathrm{~min}$ in a boiling water bath and loaded on $12.5 \%$ polyacrylamide gel. After electrophoresis, the proteins were electrically blotted on the PVDF membrane at $4^{\circ} \mathrm{C}$. The proteins in the membrane were immunochemically detected by the Avidin-Biotin-Complex (ABC) method. In this experiment, anti-hTS monoclonal antibody, anti-CDK4 monoclonal antibody, anti-pRB antibody, anti-E2F1 monoclonal antibody and anti-human $\beta$-actin antibody as primary, and anti-rabbit IgG as secondary antibodies were used, respectively.

Immunostaining. Formalin-fixed, paraffin-embedded tumor tissues were sliced to $4-\mu \mathrm{m}$ thin sections. The tissue specimen in the slide was then deparaffinized and endo- 
Table I. Effect of CPT-11 administration on activities of 5-FU-metabolizing enzymes in KM12C and KM12C/5-FU human colon tumor xenografts.

\begin{tabular}{lcccc}
\hline & \multicolumn{2}{c}{ KM12C $(\mathrm{n}=5)$} & \multicolumn{2}{c}{ KM12C/5-FU (n=5) } \\
\cline { 2 - 4 } Enzyme & Control group & CPT-11 group & & Control group \\
\hline TS & $0.290 \pm 0.045$ & $0.261 \pm 0.027$ & $1.861 \pm 0.025$ & $0.701 \pm 0.111^{\mathrm{a}}$ \\
DPD & $3.59 \pm 1.28$ & $3.21 \pm 1.88$ & ND $(<3.0)$ & $3.89 \pm 0.99$ \\
OPRT & $11.09 \pm 1.59$ & $10.88 \pm 0.62$ & $18.93 \pm 1.61$ & $17.20 \pm 1.87$ \\
TP & $0.074 \pm 0.030$ & $0.117 \pm 0.021$ & $0.150 \pm 0.018$ & $0.312 \pm 0.041^{\mathrm{a}}$ \\
RNR & $14.76 \pm 2.46$ & $9.46 \pm 1.40$ & $1.100 \pm 0.372$ & $3.898 \pm 0.390^{\mathrm{b}}$ \\
\hline
\end{tabular}

When tumors were about $200 \mathrm{~mm}^{3}, 75 \mathrm{mg} / \mathrm{kg}$ CPT-11 and saline as a control were intravenously administered to tumor-bearing mice on day 1 and 8. Twenty-four hours after CPT-11 administration, tumors were removed and homogenized to measure the enzyme activities. Specific activity units of each enzyme are as follows: TS, pmol $/ \mathrm{mg}$ protein; DPD, OPRT and RNR, pmol $/ \mathrm{min} / \mathrm{mg}$ protein; TP, $\mathrm{nmol} / \mathrm{min} / \mathrm{mg} \mathrm{protein}$. ${ }^{\mathrm{a}} \mathrm{p}<0.01,{ }^{\mathrm{b}} \mathrm{p}<0.05$, significantly different from the control group by Dunnett's test.

Table II. Time-dependent inhibition of TS activity in KM12C/5-FU tumor xenografts following single administration of $75 \mathrm{mg} / \mathrm{kg} \mathrm{CPT}-11$.

TS activity (pmol/mg protein)

Time after administration

Control group $(n=5) \quad$ CPT-11 group $(n=5)$

Inhibition rate $(\%)$

\begin{tabular}{llll}
\hline Day 2 & $2.100 \pm 0.098$ & $0.964 \pm 0.236$ & 54.1 \\
Day 4 & $1.974 \pm 0.614$ & $1.176 \pm 0.168$ & 40.5 \\
Day 6 & $1.826 \pm 0.142$ & $1.480 \pm 0.270$ & 33.1 \\
Day 8 & $1.922 \pm 0.602$ & $1.184 \pm 0.296$ & 38.4
\end{tabular}

Three weeks after tumor implantation, CPT-11 was once administered to mice bearing KM12C/5-FU tumor xenografts, and 2, 4, 6 and 8 days after, tumors were removed and their TS activity was determined.

geneous peroxidase was inactivated. After overnight exposure to anti-hPCNA monoclonal antibody (about $1 \mu \mathrm{g} / \mathrm{ml}$ ) at $4^{\circ} \mathrm{C}$, the tissue-slide was allowed to react with a reagent containing horseradish peroxidase-labeled dextran-bound anti-rabbit IgG goat polyclonal antibody (Dako Cytomation Co., Ltd., Kyoto, Japan). Colorization with 3,3'-diaminobenzidine of the tissue slide was performed for $5 \mathrm{~min}$ at room temperature, and counterstaining was performed by nuclear staining with hematoxylin.

Statistical analysis. The significance of differences between groups with or without treatment was assessed using Dunnett's test and the IUT test.

\section{Results}

Antitumor effects of the combination of $S-1$ with CPT-11 on KM12C tumor xenografts sensitive and resistant to 5-FU. As shown in Fig. 1, S-1 alone and CPT-11 alone affected significant antitumor activity with 68 and $77 \%$ inhibition rates (IR) of tumor growth, respectively, without decrease in body weight (data not shown), while the combination of S-1 with CPT-11 significantly $(\mathrm{p}<0.01)$ augmented the antitumor efficacy with $88 \%$ of IR on tumors compared with S-1 alone or CPT-11 alone. In 5-FU-resistant tumor xenografts (KM12C/ 5-FU), the antitumor activity of S-1 was less effective, only
$38 \%$ of IR while CPT-11 showed $79 \%$ of IR. However, the addition of CPT-11 with S-1 markedly and significantly potentiated the antitumor activity of S-1 and CPT-11 ( $<<0.01)$. The therapeutic activity of $\mathrm{S}-1$ in combination with CPT-11 in 5-FU-resistant tumors was similar to that in 5-FU-sensitive tumors, suggesting that CPT-11 affects sensitivity (antitumor activity) to 5-FU.

Effect of CPT-11 administration on activities of enzyme activities in 5-FU metabolism. CPT-11 (75 mg/kg) was administered weekly for 2 weeks in mice bearing KM12C and $\mathrm{KM} 12 \mathrm{C} / 5-\mathrm{FU}$ tumors, and $24 \mathrm{~h}$ later, the activity of intratumoral TS, DPD, OPRT, TP and RNR was measured, as shown in Table I. CPT-11 did not affect the activities of any of these enzymes. However, in 5-FU-resistant tumors (KM12C/5-FU), increased TS activity and decreased RNR activity in non-treated group were significantly decreased $(\mathrm{p}<0.01)$ and increased $(\mathrm{p}<0.05)$, respectively, by CPT-11 administration.

We then gave $75 \mathrm{mg} / \mathrm{kg}$ of CPT-11 to KM12C/5-FUbearing mice, and measured TS activity on days 2, 4, 6 and 8. Moderate inhibition of tumoral TS activity (40-50\%) persisted for at least one week following single administration of CPT-11. A decrease in TS proteins in the tumors was also seen from day 2 to 8 after administration of CPT-11 (Table II). 


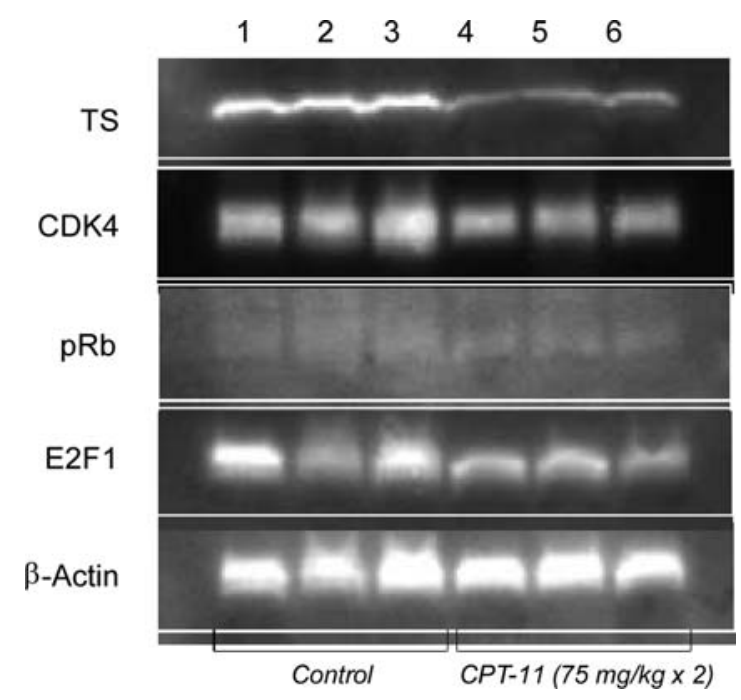

Figure 2. Expression levels of TS, CDK4, p-RB, E2F1, and B-actin in $\mathrm{kM} 12 \mathrm{C} / 5 \mathrm{FU}$ tumors treated with or without CPT-11. CPT-11 $(75 \mathrm{mg} / \mathrm{kg})$ was injected twice weekly to tumor-bearing mice, and $24 \mathrm{~h}$ after, tumors were removed and expressions of various proteins relating to cell-signaling were detected.

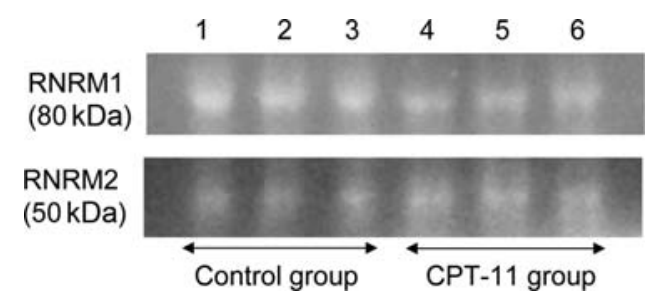

Figure 3. Expression of RNRM1 and RNRM2 in human colon cancer $\mathrm{KM} 12 \mathrm{C} / 5-\mathrm{FU}$ xenografts in mice treated with or without CPT-11. Proteins treated or not with CPT-11 were obtained with the same procedure as shown in Fig. 2.

Expression levels of TS, RNR, and cell cycle-related proteins in KM12C/5-FU tumors. Expression of TS, RNR (M1 and $\mathrm{M} 2$ ), and cell cycle-related proteins such as CDK4, pRB and E2F1 was measured by Western blot analysis in KM12C/ 5-FU tumors ( $\mathrm{n}=3$ each) before and after CPT-11 $(75 \mathrm{mg} / \mathrm{kg}$ $x$ 2) treatment. As shown in Fig. 2 (top column), downregulation of TS expression in KM12C/5-FU tumors was also confirmed by immunological analysis. As shown in Fig. 3, the RNRM2 components slightly increased following treatment with CPT-11 whereas the other component RNRM1 hardly changed, which seemed to reflect the increased RNR activity (Table I).

We detected the expression of representative cell cycleregulating proteins, $\mathrm{CDK} 4, \mathrm{pRB}$ and $\mathrm{E} 2 \mathrm{~F} 1$ in $\mathrm{KM} 12 \mathrm{C} / 5-\mathrm{FU}$ tumors, both with and without administration of CPT-11. As shown in Fig. 2, high levels of expression of CDK4 which acts as an initiator for activation of the RB-E2F complex in the $\mathrm{G} 1$ cellular phase decreased in $\mathrm{KM} 12 \mathrm{C} / 5-\mathrm{FU}$ tumors treated CPT-11, and activated (free) E2F1 and pRB proteins, which accelerate the initiation of DNA synthesis in the Sphase, were also down-regulated by treatment with CPT-11, suggesting that CPT-11 suppresses the expression of key molecules in the G1/S phase of KM12C/5-FU tumor cells,
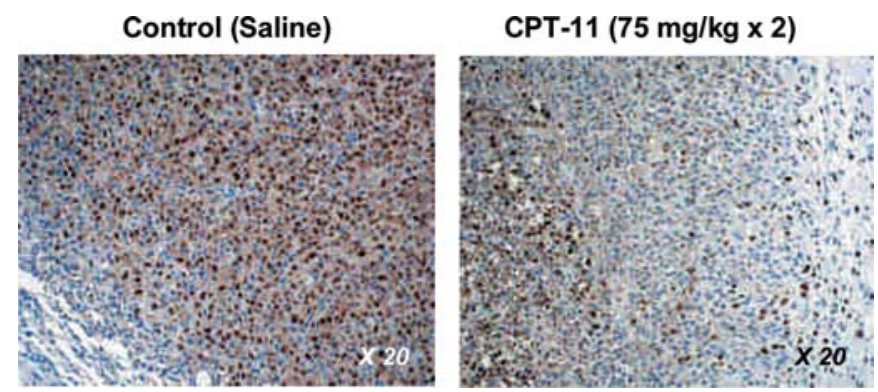

Figure 4. Immunological detection of PCNA levels in KM12C/5FU tumors treated with or without CPT-11. Tumor-bearing mice were treated with CPT-11 as shown in Fig. 2, and the expression of PCNA in surgically resected tumors was detected immunohistochemically.

resulting in the regulation of highly expressed TS proteins in DNA synthesis leading to overcome 5-FU resistance. We therefore immunohistochemically detected the expression of PCNA as a marker protein of the S-phase of the cells, and found a marked decrease of PCNA proteins in CPT-11treated KM12C/5-FU tumors (Fig. 4).

Sequential combination of CPT-11 with $S-1$ in $K M 12 C / 5-F U$ bearing mice. As CPT-11 down-regulates the overexpressed TS levels in KM12C/5-FU tumor xenografts, we examined sequential administration of CPT-11 and S-1 as a mean to control long-term antitumor efficacy in KM12C/5-FU xenografts in mice. For this, CPT-11 was administered on days 1 and 8 and sequential S-1 was given orally for 14 days starting from day 8. S-1 alone and CPT-11 alone were administered by the same schedule shown in Fig. 1 as comparative controls.

As seen in Fig. 5, the antitumor activity of CPT-11 gradually declined from $81 \%$ on day 22 to $41 \%$ of IR on day 36 , and S-1 showed less antitumor activity with about $30-36 \%$ of IR during the 36 day therapeutic period. In contrast, sequential treatment with CPT-11 followed S-1 gave a persistent growth-inhibitory activity on 5-FU-resistant tumors with $96-70 \%$ of IR throughout the therapeutic periods.

Antitumor effect of 1 -OHP plus $S$ - 1 on colon cancer xenografts sensitive and resistant to 5-FU. Based on the finding that CPT-11 augmented the antitumor activity in combination with S-1 against 5-FU-resistant colon tumor xenogragfts, we investigated whether $l$-OHP (10 mg/kg x 2) also overcome the resistance to 5-FU in $\mathrm{KM} 12 \mathrm{C} / 5-\mathrm{FU}$ tumor xenografts. In parental KM12C tumor-bearing mice, $l$-OHP did not show antitumor activity by itself, but showed a significant $(\mathrm{p}<0.0013)$ potentiated antitumor activity $(80 \%$ of IR) in combination with S-1, compared to about $70 \%$ of IR with S-1 alone. However, $l$-OHP did not augment the antitumor actitivy of S-1 agains 5-FU-resistant KM12C/5-FU tumor xenografts (Fig. 6). This result suggests that $l$-OHP may not overcome the resistance to 5-FU on 5-FU-resistant colon cancers.

We evaluated the change of TS and other enzyme activities in pyrimidine metabolism in both parental and 5-FU-resistant $\mathrm{KM} 12 \mathrm{C}$ colon tumors following administration of $l$-OHP $(10 \mathrm{mg} / \mathrm{kg} \times 2)$. As seen in Table III, treatment with $l$-OHP 
Day 22

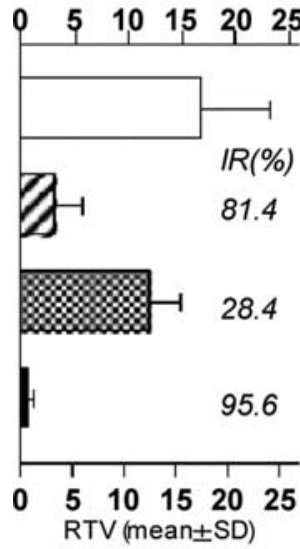

Day 25

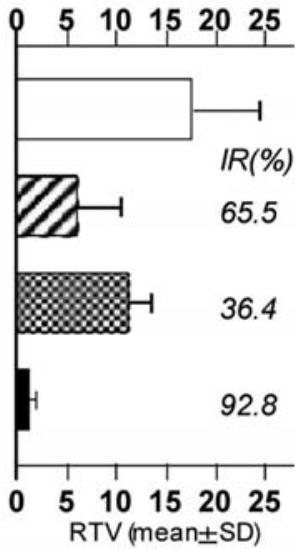

Day 29

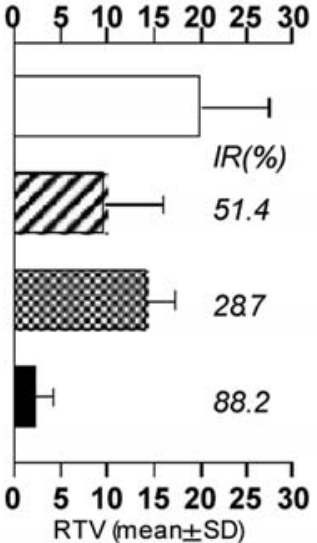

Day 36

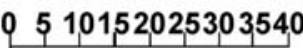

O 510152025303540

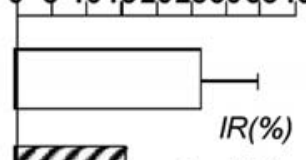

40.8

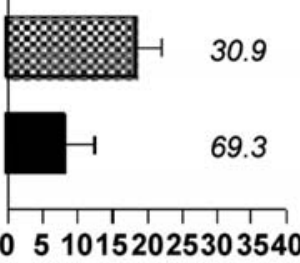

RTV (mean \pm SD)

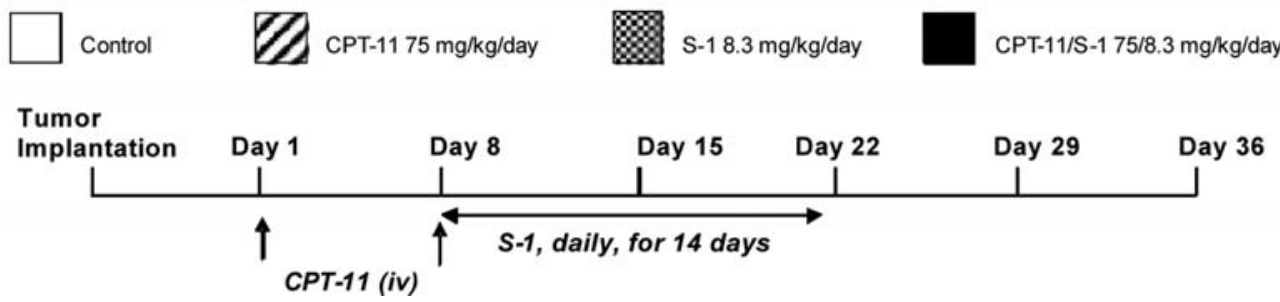

Figure 5. Antitumor effects of S-1, CPT-11, and their sequential combination on 5-FU-resistant colon cancer (KM12C/5FU) xenografts in mice. S-1 $(8.3 \mathrm{mg} / \mathrm{kg} / \mathrm{day})$ was orally given for 14 consecutive days and CPT-11 $(75 \mathrm{mg} / \mathrm{kg})$ was intravenously administered on days 1 and 8 , and 14 days after, each relative tumor volume in each treated group was measured and IR of the tumor growth was calculated. ${ }^{*} \mathrm{p}<0.01$, significantly different from S-1 alone and CPT-11 alone (IUT test).
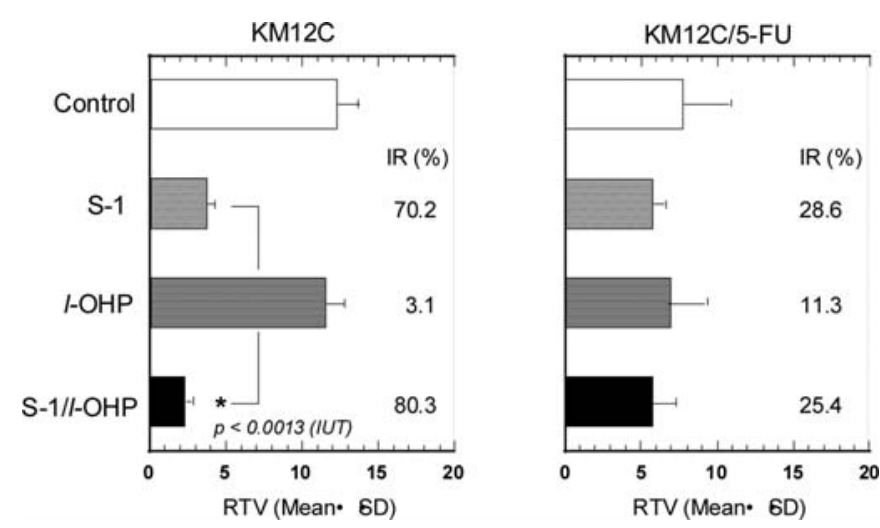

Figure 6. Antitumor effects of S-1, $l$-OHP, and their combination on parental and 5-FU-resistant colon cancer xenografts in mice. S-1 $(8.3 \mathrm{mg} / \mathrm{kg} / \mathrm{day})$ was administered daily for 14 days, and $l$-OHP $(10 \mathrm{mg} / \mathrm{kg} / \mathrm{day})$ was injected on day 1 and 8 . The antitumor activity (IR, \%) of the drugs was evaluated on day 15 after the treatment.

did not affect the activity of TS, OPRT, TP and RNR in both parental and 5-FU-resistant tumor, indicating that $l$-OHP would not improve 5-FU sensitivity via down-regulation of highly expressed TS levels.

\section{Discussion}

S-1, a novel oral fluoropyrimidine we developed, consists of $1 \mathrm{~mol}$ of tegafur, $0.4 \mathrm{~mol}$ of gimeracil which inhibits DPD activity, and $1 \mathrm{~mol}$ of oteracil which is an inhibitor of orotate phosphoribosyltransferase resulting in reduction of severe gastrointestinal toxicities. S-1 has been shown to be highly active on human tumor xenografts $(32,33)$ and gastric cancer patients $(34,35)$ with higher expression levels of tumoral DPD. Accordingly, low antitumor sensitivity of 5-FU caused by tumoral DPD would be overcome by S-1, i.e. DPDinhibitory fluoropyrimidine (DIF).

Leichman (17) reported that colorectal carcinoma patients with low TS, another response-limiting factor, would be likely to benefit from 5-FU/LV therapy, whereas those with tumors expressing high TS levels might benefit from CPT-11. Furthermore, Guichard et al (19), Pavillard et al (20) and Mans et al (21) in their in vitro studies, and Cao et al (22) and Satoh et al (23) in their in vivo animal studies indicated that combined treatment of 5-FU and CPT-11 resulted in augmented antitumor activity compared with either 5-FU or CPT-11 alone. However, none of these reports discussed whether the expression levels of tumoral TS influenced antitumor efficacy.

There may be 2 types of high expression of TS; one being originally high levels and other is elevated levels after 5-FU treatment. S-1 obtained no response in gastric cancer patients with originally high levels of TS mRNA, however, S-1 in combination with CPT-11 obtained a similar clinical response (response rate and survival) in patients with not only low levels but also high levels of TS mRNA $(34,35)$. Nevertheless, it is uncertain whether the combination of S-1 with CTP-11 results in overcoming antitumor activity in 5-FU-resistant colorectal carcinoma showing highly elevated levels of TS in both animal and clinical studies.

In the present study, we used 5-FU-resistant human colorectal cancer xenografts with highly elevated TS levels after long-term and consecutive administration of 5-FU for at least 2 years (26) to evaluate the antitumor potency of 
Table III. Effect of $l$-OHP administration on activities of 5-FU-metabolizing enzymes in KM12C and KM12C/5-FU human colon tumor xenografts.

\begin{tabular}{|c|c|c|c|c|}
\hline \multirow[b]{2}{*}{ Enzyme } & \multicolumn{2}{|c|}{$\mathrm{KM} 12 \mathrm{C}(\mathrm{n}=5)$} & \multicolumn{2}{|c|}{$\mathrm{KM} 12 \mathrm{C} / 5-\mathrm{FU}(\mathrm{n}=5)$} \\
\hline & Control group & $l$-OHP group & Control group & $l$-OHP group \\
\hline TS & $0.268 \pm 0.028$ & $0.215 \pm 0.032$ & $2.339 \pm 0.255$ & $1.943 \pm 0.186$ \\
\hline DPD & $\mathrm{ND}(<3.0)$ & $\mathrm{ND}(<3.0)$ & $\mathrm{ND}(<3.0)$ & $\mathrm{ND}(<3.0)$ \\
\hline OPRT & $20.58 \pm 1.29$ & $19.67 \pm 3.10$ & $25.04 \pm 2.73$ & $22.09 \pm 0.91$ \\
\hline TP & $0.125 \pm 0.029$ & $0.108 \pm 0.017$ & $0.153 \pm 0.020$ & $0.312 \pm 0.031^{\mathrm{a}}$ \\
\hline RNR & $12.51 \pm 0.35$ & $12.44 \pm 0.18$ & $4.125 \pm 0.382$ & $4.428 \pm 1.748$ \\
\hline
\end{tabular}

When tumors were about $300 \mathrm{~mm}^{3}, 10 \mathrm{mg} / \mathrm{kg} l$-OHP and saline as a control were intravenously administered to tumor-bearing mice on day 1 and 8 . Twenty-four hours after $l$-OHP administration, tumors were removed and homogenized to measure the enzyme activities. Specific activity units of each enzyme are as follows: TS, pmol/mg protein; DPD, OPRT and RNR, pmol/min/mg protein; TP, nmol/min/mg protein. ${ }^{\mathrm{a}} \mathrm{p}<0.05$, significantly different from the control group by Dunnett's test.

combined therapy with S-1 and CPT-11. The combination of TS-1 with CPT-11 resulted in significantly augmented antitumor effect on parental KM12C colorectal cancer xenografts compared with either S-1 alone or CPT-11 alone. Interestingly, this combination on 5-FU-resistant KM12C xenografts (KM12C/5FU) also yielded antitumor activity similar to that on parental tumors while S-1 alone obtain less effect on 5-FU-resistant tumors (Fig. 1). We therefore, measured activities of pyrimidine-metabolizing enzymes including TS, RNR and DPD in both KM12C and KM12C/ 5-FU tumors after administration of CPT-11 on days 1 and 8 . In a previous study (26), we reported marked increase of TS activity and decreased RNR activity in KM12C/5-FU tumors. We found that administration of CPT-11 resulted in both a significant decrease of originally elevated TS activity and an increase of down-regulated RNR activity in 5-FU-resistant KM12C tumors following administration of CPT-11, suggesting that down-regulation of TS activity and up-regulation of RNR activity leads to the augmented antitumor activity of 5-FU in 5-FU-resistant tumors (Table I). Western blot analysis also confirmed a significant decrease in TS proteins in KM12C/5-FU tumors following administration of CPT-11 (Table II and Fig. 2). RNR is composed of M1 and M2 subunits and exhibits activity when both M1 and M2 are conjugated. We checked the expression of both M1 and M2 proteins in KM12C/5-FU tumors treated with CPT-11 or not and found possibly increased expression of M2 proteins but not M1 proteins in the tumors treated with CPT-11. It has been suggested that when cells are damaged by anti-tumor agents, the P53-dependent M2 subunit known as P53R2 is induced to restore the damaged DNA in drug-treated cells (36). It has not yet been possible to distinguish between RNR M2 and P53R2 proteins because both anti-RNRM2 and anti-P53R2 antibodies recognize the same $50-\mathrm{kDa}$ proteins.

To further investigate the mechanism for down-regulation of elevated TS levels and up-regulation of decreased RNR levels, CDK4, one of the key cell cycle signaling proteins, and free E2F1 and phosphorylated RB (pRB) which plays an important role in regulation of the expression of S-phase proteins related to DNA synthesis in cancer cells were detected in $\mathrm{KM} 12 \mathrm{C} / 5-\mathrm{FU}$ tumors treated with $\mathrm{CPT}-11$ or not. The expression of CDK4, E2F1 and $\mathrm{pRB}$ proteins coordinating the transition from the G1 phase to the S phase of cancer cells clearly decreased following treatment with CPT-11. This phenomenon suggests that in 5-FU-resistant KM12C cells, highly expressed cyclin-D1 (data not shown) and CDK4 activate the F2F-RB complex to form free E2F1 and $\mathrm{pRB}$ proteins at the G1 phase, which causes an upregulation of TS protein functioning at the S-phase in tumor cells, and that the inhibition of DNA topoisomerase by CPT-11 possibly regulates the transition of the G1 phase to the S-phase in $\mathrm{KM} 12 \mathrm{C} / 5-\mathrm{FU}$ cells, and TS protein, as a target for 5-FU therapy, is subsequently down-regulated in 5-FU-resistant colorectal cancer cells.

As CPT-11 overcomes the resistance to 5-FU and gives a synergistic antitumor efficacy in the combination of the 5-FU prodrug, we examined the antitumor effect of sequential combination of CPT-11 followed S-1. As shown in Fig. 5, sequential administration of CPT-11 (weekly x 2) following oral S-1 (14 consecutive days) controlled the growth of KM12C/5-FU tumors for long-term periods compared with either CPT-11 alone or S-1 alone. Accordingly, sequential chemotherapy of CPT- 11 following 5-FU and its derivatives may be one of treatment options for colorectal cancer patients failed to initial treatment with 5-FU/LV or FOLFOX therapy.

We also checked the antitumor effect of the combination of $l$-OHP with oral S-1 on 5-FU-resistant colorectal cancer (KM12C/5-FU) xenografts. Unfortunately, $l$-OHP did not overcome the resistance to 5-FU even in combination with S-1 did not suppress TS levels overexpressed in the 5-FUresistant tumors. Combination therapy of $l$-OHP with fluoropyrimidines such as FLOX and FOLFOX seems to be effective for the treatment of colorectal cancer patients with low expression levels of TS.

Unlike our in vivo results, Yeh et al (37) reported that l-OHP down-regulated TS mRNA levels in their in vitro study using human colorectal cancer DLD-1 cells. Though we measured the expression levels of TS mRNA in both parental and 5-FU-resistant KM12C tumors before and after i.v. administration of $l$-OHP, there were no changes of 
TS mRNA levels following treatment with $l$-OHP (data not shown). As they did not check the expression levels of TS protein in the cells before and after 24-h treatment with $10 \mu \mathrm{M} l$-OHP, it is not possible to compare with our data.

Although alternative treatment with oxaliplatin-based and irinotecan-based regimens is at present thought to be first- and second-line therapy for advanced and metastatic colorectal cancer patients, not only combined use of highexpensive monoclonal antibodies in cytotoxic regimens such as FOLFOX and FOLFIRI but also biomarker-guided sequential treatment with cytotoxic regimens described in the present study should be considered to prolong survival in colorectal cancer patients.

\section{References}

1. O'Connell MJ: A phase III trial of 5-fluorouracil and leucovorin in the treatment of advanced colorectal cancer. Cancer 63: 1026-1030, 1989.

2. Goldberg RM, Hatfield AK, Kahn M, Sargent DJ, Knost JA, O'Connell MJ, Krook JE, Mailliard JA, Wiesenfeld M, Schaefer PL, Tirona MT and Moertel CG: Prospectively randomized North Central Cancer Treatment Group trial of intensive-course fluorouracil combined with the 1-isomer of intravenous leucovorin, oral leucovorin, or intravenous leucovorin for the treatment of advanced colorectal cancer. J Clin Oncol 15: 3320-3329, 1997.

3. Buroker TR, O'Connell MJ, SamWieand H, Krook JE, Gerstner CG and Gesme DH Jr: Randomized comparison of two schedules of fluorouracil and leucovorin in the treatment of advanced colorectal cancer. J Clin Oncol 12: 14-20, 1994.

4. De Gramont A, Figer A, Seymour M, Homerin M, Hmissi A, Cassidy J, Boni C, Corter-Funes A, Freyer G, Pamamichael D, LeBail H, Louvet C, Hendler D, de Brand F, Wilson C, Morvan F and Bonetti A: Leucovorin and fluorouracil with or without oxaliplatin as first-line treatment in advanced colorectal cancer. J Clin Oncol 18: 2938-2947, 2000.

5. Chu E: The development of the FOLFOX regimens as a treatment standard of advanced colorectal cancer. Clin Colorectal Cancer 4: 292, 2005

6. Andre T, Louvet C, Maindrault-Goebel F, Couteau C, Marbo M, Lotz JP, Gilles-Amar V, Kruli KM, Carola E, Izrael V and de Gramont A: CPT-11 (irinotecan) addition to bimonthly, high dose LV and bolus and continuous-infusion 5-fluorouracil (FOLFIRI) for pretreated metastatic colorectal cancer GERCOR. Eur J Cancer 35: 1343-1347, 1999.

7. Teufel A, Steinmann S, Siebler J, Zanke C, Hohl H, Adami B Schroeder M, Klein O, Hohler T, Galle PR, Heike M and Moehler M: Irinotecan plus folinic acid/continuous 5-fluorouracil as simplified bimonthly FOLFIRI regimen for first-line therapy of metastatic colorectal cancer. BMC Cancer 4: 38, 2004.

8. Colucci G, Gebbia V, Paoletti G, Giuliani F, Caruso M, Gebbia N, Carteni G, Agostara B, Pezzella G, Manzione L, Borsellino N, Misino A, Romito S, Durini E, Cordio S, Di Seri M, Lopez M, Maiello E, Montemurro S, Cramarissa A, Lorusso V, Di Bisceglie M, Chiarenza M, Valerio MR, Guida T, Leonardi V, Pisconti S, Rosati G, Carrozza F, Nettis G, Valdesi M, Filippelli G, Fortunato S, Mancarella S and Brunetti C; Gruppo Oncologico Dell'Italia Meridionale: Phase III randomized trial of FOLFIRI versus FOLFOX4 in the treatment of advanced colorectal cancer: a multicenter study of the Gruppo Oncologico Dell'Italia Meridionale. J Clin Oncol 23: 4866-4875, 2005.

9. Pasetto LM, Jirillo A, Ladicicco G, Rossi E, Paris MK and Monfardini S: FOLFOX versus FOLFIRI: a comparison of regimens in the treatment of colorectal cancer metastases. Anticancer Res 25: 563-576, 2005.

10. Saltz LB, Cox JV, Blanke C, Rosen LS, Fehrenbacher L, Moore MJ, Maroun JA, Ackland SP, Locker PK, Pirotta N, Flfring GL and Miller LL: Irinotecan plus fluorouracil and leucovorin for metastatic colorectal cancer. Irinotecan Study Group. N Engl J Med 343: 905-914, 2000.

11. Saltz LB, Douillard JY, Pirotta N, Alakl M, Gruia G, Awad L, Elfring GL, Locker PK and Miller LL: Irinotecan plus fluorouracil/leucovorin for metastatic colorectal cancer: a new survival standard. Oncologist 6: 81-91, 2001.
12. Shirasaka T, Shimamoto Y, Ohshimo H, Yamaguchi M, Kato T, Yonekura K and Fukushima M: Development of novel form of an oral 5-fluorouracil derivative (S-1) deirected to the potentiation of the tumor selective cytotoxicity of 5-fluorouracil by two bio-chemical modulators. Anticancer Drugs 7: 548-557, 1996.

13. Sakata Y, Ohtsu A, Horikoshi N, Sugimachi K, Mitachi Y and Taguchi T: Late phase II study of novel oral fluoropyrimidine anticancer drug S-1 (1 M tegafur-0.4 M gemestat-1 M otastat potassium) in advanced gastric cancer patients. Eur J Cancer 34: 1715-1720, 1998.

14. Koizumi W, Kurihara M, Nakano S and Hasegawa K: Phase II study of S-1, a novel oral derivative of 5-fluorouracil, in advanced gastric cancer. For the S-1 Cooperative Gastric Cancer Study Group. Oncology 58: 191-197, 2000.

15. Ohtsu A, Baba H, Sakata Y, Mitachi Y, Horikoshi N, Sugimachi K and Taguchi T: Phase II study of S-1, a novel oral fluoropyrimidine derivative, in patients with metastatic colorectal carcinoma. S-1 Cooperative Colorectal Carcinoma Study Group. Br J Cancer 83: 141-145, 2000.

16. Salonga D, Danenberg KD, Johnson M, Metzger R, Groshen S, Tsao-Wei DD, Lenz HJ, Leichman CG, Leichman L, Diasio RB and Danenberg PV: Colorectal tumors responding to 5-fluorouracil have low gene expression levels of dihydropyrimidine dehydrogenase, thymidylate synthase, and thymidine phosphorylase. Clin Cancer Res 6: 1322-1327, 2000.

17. Leichman CG: Thymidylate synthase as a predictor of response. Oncology 12: 43-47, 1998.

18. Ichikawa W, Takahashi T, Suto K, Shirota Y, Nihei Z, Shimizu M, Sasaki Y and Hirayama R: Simple combination of 5-FU pathway genes predict the outcome of metastatic gastric cancer patients treated S-1. Int J Cancer 119: 1927-1933, 2006.

19. Guichard S, Cussac D, Hennebelle I, Bugat R and Canal P: Sequence-dependent activity of the irinotecan-5FU combination in human colon-cancer model HT-29 in vitro and in vivo. Int J Cancer 73: 729-734, 1997.

20. Pavillard V, Formento P, Rostagno P, Formento JL, Fishel JL, Francoual M, Etienne MC and Milano G: Combination of irinotecan (CPT11) and 5-fluorouracil with an analysis of cellular determinants of drug activity. Biochem Pharmacol 56: 1315-1322, 1998.

21. Mans DR, Grivicich I, Peters GJ and Schwartsmann G: Sequence-dependent frowth inhibition and DNA damage formation by the irinotecan-5-flurouracil combination in human colon carcinoma cell lines. Eur J Cancer 35: 1851$1861,1999$.

22. Cao S and Rustum YM: Synergistic antitumor activity of irinotecan in combination with 5-fluorouracil in rats bearing advanced colorectal cancer: role of drug sequence and dose. Cancer Res 60: 3717-3721, 2000.

23. Satoh H, Ohtomo M, Ishikawa H, Kamma H, Yamashita YT, Ohtsuka $M$ and Sekizawa $\mathrm{K}$ : In vivo advantage of combined administration with CPT-11 and 5-fluorouracil in rats. J Exp Ther Oncol 2: 42-46, 2002.

24. Raymond E, Buquet-Fagot C, Djelloul S, Mester J, Cvitkevic E, Allain P, Louvet $\mathrm{C}$ and Gespach C: Antitumor activity of oxaliplatin in combination with 5-fluorouracil and thymidylate synthase inhibitor AG337 in human colon, breast and ovarian cancers. Anticancer Drugs 8: 876-885, 1997.

25. Peters GJ, van der Wilt CL, van Moorsel CJ, Kroep JR, Bergman AM and Ackland SP: Basis for effective combination cancer chemotherapy with antimetabolites. Pharmacol Ther 78: 227-253, 2000.

26. Fukushima M, Fujioka A, Uchida J, Nakagawa F and Takechi T: Thymidylate synthase (TS) and ribonucleotide reductase (RNR) may be involved in acquired resistance to 5-fluorouracil (5-FU) in human cancer xenografts in vivo. Eur J Cancer 37: 1681-1687, 2001.

27. Okabe H, Tsujimoto $H$ and Fukushima M: Preparation of the antibodies against recombinant human thymidylate synthase for the detection of its intratumoral levels and the application to sensitivity-study of 5-fluorouracil. Oncol Rep 4: 685-690, 1997.

28. Spears CP, Shahinian AH and Moran RG: In vivo kinetics of thymidylate synthase inhibition in 5-fluorouracil-sensitive and resistant murine colon adenocarcinomas. Cancer Res 42: 450-456, 1982.

29. Shirasaka T, Shimamoto Y and Fukushima M: Inhibition by oxonic acid of gastrointestinal toxicity of 5-fluorouracil without loss of its antitumor activity in rats. Cancer Res 53: 4004-4009, 1993. 
30. Ikenaka K, Fukushima M, Nakamura H, Okamoto M, Shirasaka T and Fujii S: Metabolism of pyrimidine nucleotides in various tissues and tumor cells from rodents. Gann 72: 590-597, 1981.

31. Maehara Y, Nakamura H, Nakane Y, Kawai K, Okamoto M, Nagayama $S$ and Shirasaka T: Activities of various enzymes of pyrimidine nucleotide and DNA synthesis in normal and neoplastic human tissues. Gann 73: 289-298, 1982.

32. Fujiwara H, Terashima M, Irinoda $\mathrm{T}$, Takagane $\mathrm{A}$, Abe $\mathrm{K}$, Nakaya T, Yonezawa H, Oyama K, Takahashi M, Saito K, Takechi T, Fukushima M and Shirasaka T: Superior antitumor activity of S-1 in tumors with a high dihydropyrimidine dehydrogenase activity. Eur J Cancer 39: 2387-2394, 2003.

33. Takechi T, Okabe H, Ikeda K, Fujioka A, Nakagawa F, Ohshimo H, Kitazato K and Fukushima M: Correlations between antitumor activities of fluoropyrimidines and DPD activity in lung tumor xenografts. Oncol Rep 14: 33-39, 2005.

34. Ichikawa W, Takahashi T, Suto K, Yamashita T, Nihei Z, Shirota Y, Shimizu M, Sasaki Y and Hirayama R: Thymidylate synthase predictive power is overcome by irinotecan combination therapy with S-1 for gastric cancer. Br J Cancer 91: 1245-1250, 2004.
35. Takiuchi H, Kawabe S, Gotoh M and Katsu K: Thymidylate synthase gene expression in primary tumors predicts activity of S-1-based chemotherapy for advanced gastric cancer. Gastrointest Cancer Res 1: 172-177, 2007.

36. Guittet O, Hakansson P, Voevodskaya N, Fridd S, Graslund A, Arakawa H, Nakamura Y and Thelander L: Mammalian p53R2 protein forms as active ribonucleotide reductase in vitro with the $\mathrm{R} 1$ protein, which is expressed both in resting cells in response to DNA damage and in proliferating cells. J Biol Chem 276: 40647-40651, 2001.

37. Yeh KH, Cheng AL, Wan JP, Lin CS and Liu CC: Downregulation of thymidylate synthase expression and its steadystate mRNA by oxaliplatin in colon cancer cells. Anticancer Drugs 15: 371-376, 2004. 